University of Nebraska - Lincoln

DigitalCommons@University of Nebraska - Lincoln

Faculty Publications: Department of

Entomology

Entomology, Department of

April 1997

\title{
Susceptibility of Stable Flies (Diptera: Muscidae) from \\ Southeastern Nebraska Beef Cattle Feedlots to Selected \\ Insecticides and Comparison of 3 Bioassay Techniques
}

\author{
Paula C. R. G. Marcon \\ University of Nebraska-Lincoln \\ Gustave D. Thomas \\ University of Nebraska-Lincoln \\ Blair Siegfried \\ University of Nebraska-Lincoln, bsiegfried1@ufl.edu \\ John B. Campbell \\ University of Nebraska-Lincoln, jcampbell1@unl.edu
}

Follow this and additional works at: https://digitalcommons.unl.edu/entomologyfacpub

Part of the Entomology Commons

Marcon, Paula C. R. G.; Thomas, Gustave D.; Siegfried, Blair; and Campbell, John B., "Susceptibility of Stable Flies (Diptera: Muscidae) from Southeastern Nebraska Beef Cattle Feedlots to Selected Insecticides and Comparison of 3 Bioassay Techniques" (1997). Faculty Publications: Department of Entomology. 59.

https://digitalcommons.unl.edu/entomologyfacpub/59

This Article is brought to you for free and open access by the Entomology, Department of at DigitalCommons@University of Nebraska - Lincoln. It has been accepted for inclusion in Faculty Publications: Department of Entomology by an authorized administrator of DigitalCommons@University of Nebraska - Lincoln. 


\title{
Susceptibility of Stable Flies (Diptera: Muscidae) from Southeastern Nebraska Beef Cattle Feedlots to Selected Insecticides and Comparison of 3 Bioassay Techniques
}

\author{
PAULA C.R.G. MARÇON, GUSTAVE D. THOMAS, ${ }^{1}$ BLAIR D. SIEGFRIED, AND \\ JOHN B. CAMPBELL 2
}

Department of Entomology, University of Nebraska, Lincoln, NE 68583-0816

\begin{abstract}
J. Econ. Entomol. 90(2): 293-298 (1997)
ABSTRACT Insecticide susceptibility of field populations of stable flies, Stomoxys calcitrans (L.), was assayed using 3 exposure techniques: treated filter papers, treated glass petri dishes, and topical applications. Both topical applications and residual exposure to treated glass surfaces were suitable for testing susceptibility of stable flies to permethrin, stirofos, or methoxychlor. Residues on filter papers yielded inconsistent results with stirofos and methoxychlor. Significant concentration-mortality regression lines were generated with permethrin residues on filter papers, but $\approx 1,000$ times more insecticide was required to produce a toxic response when compared with permethrin residues on glass. Because of higher variability in response and the greater amount of insecticide required, residues on filter papers do not appear appropriate to test insecticide susceptibility in stable flies. Paired comparisons of field $(\mathrm{F})$ and susceptible $(\mathrm{S})$ stable flies resulted in field to susceptible ratios significantly $>1.0$ only when the flies were treated topically, which suggests that topical application is more sensitive than residues on glass for the insecticides tested. Topical treatment with permethrin resulted in one $\mathrm{FS}\left(\mathrm{LD}_{90}\right)$ of 1.8 -fold. Topical treatment with methoxychlor resulted in one $\mathrm{FS}\left(\mathrm{LD}_{90}\right)$ of 3.4-fold. However, the magnitude of these ratios is not larger than the significant differences observed within the susceptible laboratory colony from one generation to another. Intense exposure to insecticides is not known to have occurred in these field populations, indicating that the observed differences are the result of natural variation among stable fly populations and unrelated to prior selection with insecticides.
\end{abstract}

KEY WORDS Stomoxys calcitrans, insecticide resistance, insecticide susceptibility, bioassay

The STABLE FLY, Stomoxys calcitrans (L.), is an economically important bloodsucking pest of feedlot and dairy cattle (Bruce and Decker 1958, Berry et al. 1983, Morgan et al. 1983, Campbell et al. 1987). In the United States, annual losses in cattle production caused by this pest have been estimated at $\$ 398.8$ million (Drummond et al. 1981).

Historically, stable fly control has been directed at adult populations and relies mainly on the use of insecticides. However, little information is available on insecticide susceptibility of field stable fly populations when compared with the house fly and other arthropod species. Resistance in stable flies was reported to DDT, lindane, and chlordane, with cross resistance to dieldrin (Somme 1958, 1962; McDuffie 1960; Drummond 1977). Mount (1965) reported resistance in stable flies to dieldrin in the United States, and Harris et al. (1972) tested strains of stable flies

\footnotetext{
This article reports the results of research only. Mention of a proprietary product does not constitute an endorsement or a recommendation for its use by USDA.

${ }^{1}$ Midwest Livestock Insects Res. Laboratory, USDA-ARS, 305 Plant Industry Building, University of Nebraska-Lincoln, Lincoln, NE 68583-0938.

${ }^{2}$ University of Nebraska, West Central Research and Extension Center, Rural Route 4 Box 46A, North Platte, NE 69101.
}

from South Africa and detected resistance to toxaphene and lindane. More recently, Cilek and Greene (1994) found resistance to dichlorvos (237.6-fold), and some degree of tolerance to stirofos (4.6-fold), and permethrin (1.8-fold) in stable fly populations from southeastern Kansas.

In assessing insecticide susceptibility, it is critical to choose a bioassay technique that is precise and sensitive enough to detect changes in susceptibility status of field populations as they occur. In the study reported here, 3 bioassay techniques were compared to determine which would be more sensitive for resistance detection in stable fly populations. These techniques were used to evaluate permethrin, stirophos, and methoxychlor in field populations of stable flies from southeastem Nebraska.

\section{Materials and Methods}

Insecticides. All insecticides used were technical grade and diluted in either reagent-grade chloroform (stirofos residues on filter paper) or acetone (all others). Permethrin (94.6\% [AI] maximum $55 \% \pm$ cis and minimum $45 \% \pm$ trans) was obtained from FMC (Philadelphia, PA), sti- 
rofos $(99 \%[\mathrm{AI}])$ was supplied by Fermenta Animal Health (Kansas City, MO), and methoxychlor (95.6\% [AI]) was obtained from Kincaid Enterprise (Nitro, WV).

Stable Flies. The insecticide-susceptible laboratory colony of stable flies used in this study originated from pupae of the Kerrville Strain (Knipling-Bushland U.S. Livestock Insects Laboratory, Kerrville, TX). This strain was used as a standard reference for insecticide susceptibility because it has been isolated from insecticide exposure since 1952. In the 1st yr of this study, field stable flies were collected from 3 feedlots in 2 southeastern Nebraska counties: feedlots A and C in Saunders County and feedlot B in Lancaster County. In the 2nd yr, only feedlots A and B were sampled. Population A had a record of recent insecticide use (adult fly control with permethrin using a mist blower) whereas the other two feedlots (B and $\mathrm{C}$ ) had not been sprayed for $2 \mathrm{yr}$. We were unable to obtain accurate historical records of insecticide applications in the region, although use of insecticides for fly control was minimal.

Adult field stable flies were collected from the legs of a calf using the stanchioned-calf vacuuming technique (Thomas et al. 1989). After collection, field flies were transferred immediately to cages and transported to the laboratory. Bioassays were performed on the day of capture, usually within 2 $\mathrm{h}$. Both males and females were used in the bioassays, representing a random sample from field collections. Insecticide-susceptible laboratory flies were tested at 3-5 d of age. After treatment, test insects were kept in an incubator at $25^{\circ} \mathrm{C} \pm 1$ and a photoperiod of 12:12 (L:D) h.

Exposure to Residues on Filter Papers. Treated filter papers $(9 \mathrm{~cm}$ diameter, grade 1 , Whatman, Hillsboro, OR) were prepared by applying $1 \mathrm{ml}$ of the appropriate solution to each filter paper and allowing them to dry. The treated filter papers were then wrapped in aluminum foil packets and stored at $4^{\circ} \mathrm{C}$ until used in bioassays (no longer than $3 \mathrm{~d}$ ). According to Sheppard and Hinkle (1987), treated filter papers kept in foil packets can be used for 6 mo or longer. Eleven concentrations were used for all bioassays. Controls consisted of filter papers treated only with acetone (permethrin and methoxychlor bioassays) or chloroform (stirofos bioassays). Flies were aspirated from the cage and counted on a chilling table. Each bioassay consisted of 3 complete tests using 3 groups of 20 flies from each population for each treatment level in a test. Plastic petri dishes ( 100 by $15 \mathrm{~mm}$ standard, Fisher, St. Louis, MO) were used to expose flies to treated filter papers, and lids were perforated to allow air flow. Test flies were placed on the untreated petri dish cover to allow them to recover from anesthesia. Each petri dish was provided with a water-saturated dental wick placed on the petri dish bottom. Three replications were performed with each of the 3 insecticides on the insecticide- susceptible laboratory colony. This technique was used during the 1st yr of the study.

Exposure to Residues on Glass Petri Dishes. Serial dilutions were prepared from a stock solution to produce 5-10 concentrations. Acetone was used as the solvent for all insecticides. Each bioassay consisted of 3 complete tests using 3 groups of 20 flies from each population for each treatment level in a test. Each test was composed of 5-10 concentrations. Standard glass petri dishes were used (interior bottom diameter of $9 \mathrm{~cm}$ ). For each concentration, $2 \mathrm{ml}$ of the appropriate solution were applied to the bottoms of 3 petri dishes and distributed uniformly by gently rotating the dishes while drying. Acetone alone was applied in a similar manner to each of the 3 control dishes. After treatment, the dishes were allowed to air dry for $\approx 3 \mathrm{~h}$ and then covered and stored in darkness at room temperature for at least $24 \mathrm{~h}$ before use (no longer than $1 \mathrm{wk}$ ).

Before each bioassay, test flies were anesthetized using $\mathrm{CO}_{2}$, separated into groups of 20 , and placed into small screened containers. After all insects had been grouped, flies were anesthetized lightly again and placed in the respective petri dishes. Test flies were placed on the untreated petri dish cover to allow them to recover from anesthesia. Each petri dish was provided with a water-saturated dental wick placed on the petri dish bottom. Each time a field fly population was tested, a simultaneous test was performed on the reference susceptible population. This technique was used in the $2 \mathrm{nd} \mathrm{yr}$ of the study.

Topical Exposure. Stable flies were separated into groups of 15 and placed in disposable cups before treatment. Cups containing 15 flies were assigned randomly to each of 3 tests and, within a test, to each dose treatment. Each bioassay consisted of 3 complete tests using 3 groups of 15 flies of each population for each treatment level in a test, and each test was composed of 5-10 dose levels. Acetone was used as the solvent for all the insecticides. All serial dilutions were prepared the day before being used.

Flies were anesthetized with $\mathrm{CO}_{2}$ and $1 \mu \mathrm{l}$ of the appropriate solution was applied to the notum of each fly using an Eppendorf micropipette (0.5$10.0 \mu \mathrm{l}$, Brinkmann, Westbury, NY). Controls were treated with acetone only. After treatment, flies were placed in paper cups $(114 \mathrm{ml})$ that were covered with tulle cloth and secured with rubber bands. A water-saturated dental wick was placed on the bottom of each cup.

This technique was used in the 2nd yr of the study. Each time a field fly population was tested, a simultaneous test was performed on the reference susceptible laboratory population. Before each bioassay, a sample of $\approx 100$ stable flies was weighed to determine mean weights for each population on each bioassay date. This allowed us to convert lethal dose values from micrograms per fly to micrograms per milligram of body weight. 
Table 1. Susceptibility of stable flies from southeastern Nebraska to permethrin residues on filter papers

\begin{tabular}{|c|c|c|c|c|c|c|}
\hline Population & $n$ & Slope \pm SE & $\mathrm{LC}_{50}\left(\mathrm{FL}_{95 \%}\right)^{a}$ & $\mathrm{LC}_{90}(\mathrm{FL} 95 \%)^{a}$ & $\mathrm{FS}\left(\mathrm{LC}_{50}\right)$ & FS $\left(\mathrm{LC}_{90}\right)$ \\
\hline Susceptible & 651 & $5.77 \pm 0.54$ & $1.450(1.212-1.680)$ & $2.418(2.042-3.220)$ & - & - \\
\hline Feedlot $\mathrm{A}^{b}$ & 658 & $3.57 \pm 0.48$ & $1.936(1.159-2.621)$ & $4.420(3.178-9.939)$ & 1.3 & 1.8 \\
\hline Feedlot $A^{b}$ & 654 & $3.39 \pm 0.31$ & $1.470(1.263-1.714)$ & $3.511(2.870-4.632)$ & 1.0 & 1.5 \\
\hline Feedlot B & 658 & $3.94 \pm 0.53$ & $1.342(1.036-1.630)$ & $2.835(2.288-3.978)$ & 0.9 & 1.2 \\
\hline Feedlot C & 655 & $3.83 \pm 0.52$ & $0.940(0.430-1.282)$ & $2.043(1.531-3.736)$ & 0.7 & 0.8 \\
\hline
\end{tabular}

Values within a column were not significantly different $(P>0.050)$. Significance of differences determined by likelihood ratio test for equality followed by pairwise comparisons using nonoverlapping fiducial limits (Savin et al. 1977). Field to susceptible (FS) ratio $=$ lethal concentration (LC) value of the field population divided by the lethal concentration value of the reference susceptible strain.

a Micrograms $(\mathrm{AI}) / \mathrm{cm}^{2}$.

${ }^{b}$ Feedlot A was sampled on 2 different occasions.

Data Collection and Statistical Analysis. For all exposure techniques, mortality was recorded at 2,4 , and $24 \mathrm{~h}$ after exposure. Flies unable to stand upright were recorded as dead. Dose-mortality data were subjected to probit analysis (Finney 1971) using POLO-PC (LeOra Software 1987). Field to susceptible ratios were calculated by dividing the lethal concentration value (residual exposure) or lethal dose value (topical treatment) of field populations by the corresponding value of the reference susceptible population. Significance of differences was determined by the likelihood test for equality of the lethal concentration or lethal dose values used to compute the ratios, followed by pairwise comparisons using nonoverlapping fiducial limits (Savin et al. 1977).

\section{Results}

For all exposure techniques, insecticide exposure of stable flies for $4 \mathrm{~h}$ produced less variable results than when flies were exposed for only $2 \mathrm{~h}$. The 24-h exposure period resulted in high control mortality $(>30 \%)$ of field-collected stable flies in many of the bioassays, regardless of technique.
Therefore, only results from the 4-h exposure are presented.

Exposure to Residues on Filter Papers. Permethrin was the only insecticide that produced data that could be analyzed by probit analysis as determined by the chi-square goodness-of-fit test. However, the lethal concentration values obtained by this technique (Table 1) were at least 1,000 times greater than those obtained by exposure to permethrin residues on glass petri dishes (Table 2). Susceptibility of field stable flies to permethrin residues on filter papers was not significantly different from that of the susceptible strain (Table 1).

Exposure to stirofos resulted in low mortality of field stable flies from feedlots A and B (36.1 and $44.8 \%$, respectively) at the highest concentration tested $\left(200 \mu \mathrm{g} / \mathrm{cm}^{2}\right)$, which was at least 1,000 times greater than the concentration needed to cause $90 \%$ mortality on the same populations by exposure to residues on glass petri dishes (Table 2). Population $\mathrm{C}$ and the susceptible laboratory colony were tested up to $600 \mu \mathrm{g} / \mathrm{cm}^{2}$, and although higher mortality was achieved at that concentration (78.7 and $95.0 \%$, respectively), oscillation in response

Table 2. Susceptibility of stable flies from southeastern Nebraska to insecticide residues on glass petri dishes

\begin{tabular}{|c|c|c|c|c|c|c|}
\hline Population & $n$ & Slope $\pm S E$ & $\mathrm{LG}_{50}\left(\mathrm{FL}_{95 \%}\right)^{a}$ & $\mathrm{LC}_{90}\left(\mathbf{F} \mathrm{L}_{95 \%}\right)^{a}$ & $\mathrm{FS}\left(\mathrm{LC}_{50}\right)^{a}$ & FS $\left(\mathrm{LC}_{90}\right)^{a}$ \\
\hline \multicolumn{7}{|c|}{ Permethrin } \\
\hline Susceptible & 472 & $4.59 \pm 0.49$ & $0.001(0.001-0.002)$ & $0.003(0.002-0.003)$ & - & - \\
\hline Feedlot A & 467 & $3.73 \pm 0.51$ & $0.001(0.001-0.001)$ & $0.002(0.002-0.003)$ & 1.0 & 0.7 \\
\hline Susceptible & 480 & $4.96 \pm 0.54$ & $0.001(0.001-0.001)$ & $0.002(0.002-0.003)$ & - & - \\
\hline Feedlot B & 474 & $3.41 \pm 0.36$ & $0.001(0.001-0.001)$ & $0.002(0.002-0.003)$ & 1.0 & 1.0 \\
\hline \multicolumn{7}{|c|}{ Stirofos } \\
\hline Susceptible & 480 & $6.82 \pm 0.66$ & $0.100(0.093-0.109)$ & $0.155(0.139-0.179)$ & - & - \\
\hline Feedlot A & 478 & $3.97 \pm 0.46$ & $0.028(0.018-0.036)$ & $0.060(0.046-0.108)$ & $0.3 *$ & $0.4^{*}$ \\
\hline Susceptible & 480 & $10.05 \pm 1.18$ & $0.095(0.086-0.105)$ & $0.128(0.114-0.157)$ & - & - \\
\hline Feedlot B & 447 & $5.11 \pm 1.17$ & $0.036(0.025-0.043)$ & $0.065(0.057-0.080)$ & $0.4^{*}$ & $0.5^{*}$ \\
\hline \multicolumn{7}{|c|}{ Methoxychlor } \\
\hline Susceptible & 412 & $3.18 \pm 0.32$ & $0.072(0.052-0.090)$ & $0.181(0.139-0.289)$ & 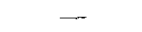 & - \\
\hline Feedlot A & 410 & $2.57 \pm 0.27$ & $0.098(0.084-0.114)$ & $0.309(0.242-0.446)$ & 1.4 & 1.7 \\
\hline Susceptible & 480 & $2.31 \pm 0.23$ & $0.117(0.098-0.135)$ & $0.419(0.336-0.573)$ & - & - \\
\hline Feedlot B & 417 & $2.86 \pm 0.29$ & $0.081(0.069-0.094)$ & $0.228(0.185-0.311)$ & 0.7 & 0.5 \\
\hline
\end{tabular}

Field to susceptible (FS) ratio = lethal concentration (LC) value of the field population divided by the lethal concentration value of the reference susceptible strain. *, Field to susceptible ratios significantly $<1.0(P>0.050)$, as determined by the likelihood test for equality of the lethal concentration values followed by pairwise comparisons using nonoverlapping fiducial limits (Savin et al. 1977).

${ }^{a}$ Micrograms $(\mathrm{AI}) / \mathrm{cm}^{2}$ 
Table 3. Susceptibility of stable flies from southeastern Nebraska to topically applied insecticides

\begin{tabular}{|c|c|c|c|c|c|c|c|}
\hline Population & $n$ & Wt, $\mathrm{mg}^{a}$ & Slope \pm SE & $\begin{array}{l}\mathrm{LD}_{50}\left(\mathrm{FL}_{95 \%}\right) \\
(\mu \mathrm{g} / \mathrm{mg} \text { body wt })\end{array}$ & $\begin{array}{c}\mathrm{LD}_{90}\left(\mathrm{FL}_{95 \%}\right) \\
(\mu \mathrm{g} / \mathrm{mg} \text { body wt })\end{array}$ & FS $\left(\mathrm{LD}_{50}\right)$ & FS $\left(L D_{90}\right)$ \\
\hline \multicolumn{8}{|c|}{ Permethrin } \\
\hline Susceptible & 358 & 15.64 & $4.78 \pm 0.45$ & $0.13(0.06-0.13)$ & $0.19(0.13-0.19)$ & - & - \\
\hline Feedlot A & 360 & 17.16 & $2.92 \pm 0.31$ & $0.12(0.12-0.17)$ & $0.35(0.23-0.82)$ & 0.9 & $1.8^{*}$ \\
\hline Susceptible & 359 & 12.53 & $3.20 \pm 0.34$ & $0.08(0.08-0.16)$ & $0.24(0.16-0.32)$ & - & - \\
\hline Feedlot $\mathbf{B}^{b}$ & 356 & 10.35 & $2.38 \pm 0.30$ & $0.10(-)$ & $0.39(-)$ & 1.3 & 1.6 \\
\hline \multicolumn{8}{|c|}{ Stirofos } \\
\hline Susceptible & 408 & 10.34 & $5.72 \pm 1.29$ & $0.29(0.19-0.29)$ & $0.48(0.39-0.77)$ & - & - \\
\hline Feedlot A & 400 & 10.37 & $3.10 \pm 0.38$ & $0.96(0.77-1.16)$ & $2.41(1.83-3.47)$ & $3.3^{*}$ & $5.0^{*}$ \\
\hline Susceptible & 315 & 13.18 & $4.75 \pm 0.70$ & $0.68(0.38-0.83)$ & $1.29(0.99-2.50)$ & - & -- \\
\hline Feedlot B & 311 & 10.93 & $3.01 \pm 0.32$ & $0.91(0.64-1.28)$ & $2.56(1.83-4.57)$ & 1.3 & 2.0 \\
\hline \multicolumn{8}{|c|}{ Methoxychlor } \\
\hline Susceptible & 312 & 8.86 & $2.49 \pm 0.54$ & $3.16(1.58-4.40)$ & $10.38(8.13-15.58)$ & - & - \\
\hline Feedlot A & 301 & 10.40 & $2.77 \pm 0.42$ & $5.10(3.85-6.35)$ & $14.90(11.83-21.54)$ & 1.6 & 1.4 \\
\hline Susceptible & 314 & 13.63 & $9.05 \pm 1.26$ & $4.33(3.89-4.77)$ & $5.94(5.36-6.97)$ & - & - \\
\hline Feedlot B & 313 & 10.14 & $2.61 \pm 0.35$ & $6.51(4.73-8.19)$ & $20.02(14.99-32.15)$ & 1.5 & $3.4^{*}$ \\
\hline
\end{tabular}

Lethal dose values and respective fiducial limits are multiplied by a factor of 1,000 . Field to susceptible ratio $=$ lethal dose value of the field population divided by the lethal dose value of the reference susceptible strain. ${ }^{*}$, Field to susceptible ratios significantly $>1.0$ $(P>0.050)$, as determined by the likelihood test for equality of the lethal dose values followed by pairwise comparisons using nonoverlapping fiducial limits (Savin et al. 1977).

${ }^{a}$ Average weight of a sample of 100 stable flies from each collection/bioassay date.

${ }^{b}$ Fiducial limits could not be estimated because $g$ (index of significance for potency estimation [Finney 1971] $>0.5$ ).

with increasing concentrations resulted in poor fit of these data to the probit model (data not shown).

Dose-response of stable flies to methoxychlor was also inconsistent, especially in the susceptible laboratory population where response at the highest concentrations $\left(100-600 \mu \mathrm{g} / \mathrm{cm}^{2}\right)$ varied between 50 and $100 \%$. As with the other insecticides, the highest concentrations tested were at least 1,000 times greater than the concentration needed to cause a $90 \%$ mortality in the same populations by exposure to residues on glass petri dishes (Table 2).

Exposure to Residues on Glass Petri Dishes. This bioassay technique yielded suitable results for testing the susceptibility of stable flies to permethrin, stirofos, and methoxychlor. The slopes of the regression lines tended to be steeper with this technique relative to topical application, although differences were not significant. The susceptibility of field-collected stable flies was not significantly lower than that of the susceptible strain for any of the 3 insecticides tested. In fact, some lethal concentration values (stirofos) were lower when compared with the corresponding value of the susceptible population, as can be noted by the field to susceptible ratios significantly $<1.0$ (Table 2 ).

Topical Exposure. Field to susceptible ratios significantly $>1.0$ were detected only when flies were treated topically, which suggests this technique is more precise. Stable flies from feedlot A treated topically with permethrin showed an $\mathrm{FS}\left(\mathrm{LD}_{90}\right)$ ratio of 1.8 (Table 3 ). The same trend was observed for stable flies from feedlot B, but significance of differences could not be assessed because the data did not allow for fiducial limits to be estimated (index of significance for potency estimation (g) $>0.5$, Finney 1971). Stable flies from feedlot A treated topically with stirofos showed an $\mathrm{FS}\left(\mathrm{LD}_{50}\right)$ ratio of 3.3 and an $\mathrm{FS}\left(\mathrm{LD}_{90}\right)$ of 5.5 (Table 3 ). However, this may not indicate resistance of the field population because it coincides with a significant increase in the susceptibility of the laboratory population tested on that date relative to other bioassay dates (2.3-fold). Topical exposure of stable flies from feedlot B to methoxychlor resulted in a $\mathrm{FS}\left(\mathrm{LD}_{90}\right)$ ratio significantly $>1.0$ (3.4-fold). The same trend was observed in stable flies from feedlot $A$, but the observed difference was not statistically significant.

\section{Discussion}

Results from this study indicate that residues on glass and topical applications are suitable for bioassay of insecticide susceptibility in stable flies. Residues on filter papers yielded inconsistent results with stirofos and methoxychlor, and although significant concentration-mortality regression lines were generated with permethrin residues on filter papers, at least 1,000 times more insecticide was required to produce a toxic response relative to residues on glass. The greater sensitivity of the latter method is especially important in estimating susceptibility to low residue amounts. Because of the high variability in these data and the much greater amounts of insecticide required, residues on filter papers are not recommended to test insecticide susceptibility in stable flies. Thus, the rest of the discussion will focus only on the 2 techniques that did yield reliable results: residues on glass and topical application.

Field to susceptible ratios significantly $>1.0$ were observed only when the flies were treated topically (which allowed for corrections in body 
weight differences between the laboratory and field population). However, the magnitude of these ratios was small $(<3.5$-fold $)$ and comparable to ratios obtained when the susceptible colony was tested on different dates (data not shown). Therefore, we believe these ratios are not indicative of resistance to the insecticides tested, but rather reflects natural variation in response of stable flies. The existence of shifting response curves in different generations of insecticide susceptible colonies has been reported previously in the stable fly (Harris et al. 1972) and in other insect species (Savin et al. 1977). This emphasizes the need for periodic testing of laboratory populations, because such changes may alter comparison ratios and therefore result in misclassification of a field population as to its resistance status.

In most paired comparisons, the slope of the regression line for the field population was significantly less steep $(P<0.05)$ than that of the susceptible population in the paired bioassay, for both techniques. For each insecticide, slopes obtained from either the susceptible or field populations tended to be slightly steeper with the glass residue method than with topical application, although differences were not significant. Although significant field to susceptible ratios were detected only when flies were treated topically, suggesting it is a more sensitive method, it is important to recognize that residues on glass more closely approximate the mode of exposure of flies to residual insecticides in feedlots and it allows for dishes to be prepared in advance and sent to different locations for testing. Development of a diagnostic bioassay using residues on glass should significantly improve the efficiency of this technique in resistance monitoring.

In a similar study, topical application was recommended over residues on glass for testing DDT resistance in house flies (Dahm et al. 1961). However, residues on glass proved to be a more sensitive method for testing pyrethroid resistance in horn flies (Hinkle et al. 1985, Sheppard and Hinkle 1986). This reinforces the importance of testing the appropriateness of different bioassay techniques for assessing susceptibility in any given insecticide-insect system before recommendations are made for large scale monitoring. Stable fly populations should continue to be surveyed for resistance to the insecticides currently used and to evaluate new insecticides that are developed for stable fly control. Further research is needed to develop more practical resistance detection techniques, so that efficient areawide monitoring programs can be established.

\section{Acknowledgments}

We thank H. R. Meyer (Department of Entomology, North Dakota State University, Fargo) for supplying insecticides and for the treatment of the filter papers. We also thank S. E. Kunz (Knipling-Bushland U.S. Livestock
Insects Laboratory, Kerrville, TX) for providing insecticide-susceptible stable flies for this study. Finally, we thank S. Skoda, D. Berkebile, and T. Spencer for their help in conducting the experiments and also for their useful comments on the manuscript. This study was conducted in cooperation with the Institute of Agriculture and Natural Resources, University of Nebraska, Lincoln, NE. Published as Paper No. 10441, Journal Series, Nebraska Agricultural Research Division.

\section{References Cited}

Berry I. L., D. A. Stage, and J. B. Campbell. 1983. Population and economic impact of stable flies on cattle. Trans. ASAE (Am. Soc. Agric. Eng.) 26: 873-877.

Bruce, W. N., and G. C. Decker. 1958. The relationship of stable fly abundance to milk production in dairy cattle. J. Econ Entomol. 51: 269-274.

Camphell, J. B., I. L. Berry, D. J. Boxler, R. L. Davis, D. C. Clanton, and G. H. Deutscher. 1987. Effects of stable flies (Diptera: Muscidae) on weight gain and feed efficiency on feedlot cattle. J. Econ. Entomol. 80: 117-119.

Cilek, J. E., and G. L. Greene. 1994. Stable fly (Diptera: Muscidae) insecticide resistance in Kansas cattle feedlots. J. Econ. Entomol. 87: 275-279.

Dahm, P. A., J. Gurland, I. Lee, and J. Berlin. 1961. A comparison of some house fly bioassay methods. J. Econ. Entomol. 54: 343-347.

Drummond, R. O. 1977. Resistance in ticks and insects of veterinary importance, pp. 303-319. In D. L. Watson and A. W. Brown [eds.]. Pesticide management and insecticide resistance. Academic, Washington, DC.

Drummond, R. O., G. Lambert, H. E. Smalley, Jr., and C. E. Terrill. 1981. Estimated losses of livestock to pests, pp. 111-127. In D. Pimentel [ed.], CRC handbook of pest management in agriculture. CRC, Boca Raton, FL.

Finney, D. J. 1971. Probit analysis. Cambridge University Press, Cambridge.

Harris, R. L., O. H. Graham, and E. D. Frazar. 1972. Susceptibility of five strains of stable flies to certain insecticides. J. Econ. Entomol. 65: 915-916.

Harris, E. G., J.E.H. Grose, and M. L. Zammit. 1976. Control of farm flies in Malta-I. Toxicities of insecticides to laboratory and Maltese field strains of Musca domestica and Stomoxys calcitrans. PANS (Pest Artic. News Summ.) 22: 202-206.

Hinkle, N. C., D. C. Sheppard, and M. P. Nolan, Jr. 1985. Comparing residue exposure and topical application techniques for assessing resistance in house flies (Diptera: Muscidae). J. Econ. Entomol. 78: 722724.

LeOra Software. 1987. POLO-PC. A user's guide to probit analysis or logit analysis. LeOra Software, Berkeley. CA.

MeDuffie, W. C. 1960. Current status of insecticide resistance in livestock pests. Entomol. Soc. Am. Misc. Publ. 2: 49-54.

Morgan, C. E., G. D. Thomas, and R. D. Hall. 1983. Annotated bibliography of the stable fly, Stomoxys calcitrans (L.), including references on other species belonging to the genus Stomoxys. North Cent. Reg. Res. Publ. No. 291. Univ. Mo. Agric. Exp. Stn. Res. Bull. 1049. 
Mount, G. A. 1965. Use of the WHO tsetse fly kit for determining resistance in the stable fly. J. Econ. Entomol. 58: 794-796.

Savin, N. E., J. L. Robertson, and R. M. Russell. 1977. A critical evaluation of bioassay in insecticide research: likelihood ratio tests of dose-mortality regression. Bull. Entomol. Soc. Am. 23: 257-266.

Sheppard, D. C., and N. C. Hinkle. 1986. A procedure for evaluation of horn fly, Haematobia irritans (L.), pyrethroid resistance by exposure to pyrethroid residues on glass. J. Agric. Entomol. 3: 100-102.

1987. A field procedure using disposable materials to evaluate horn fly insecticide resistance. J. Agric. Entomol. 4: 87-89.
Somme, L. 1958. The number of stable flies in Norwegian barns and their resistance to DDT. J. Econ. Entomol. 51: 599-601.

1962. Notes on resistance to chlorinated hydrocarbon insecticides in the stable fly, Stomoxys calcitrans (L.) (Diptera). Nors. Entomol. Tidskr. 12: 11-16.

Thomas, G. D., I. L. Berry, D. R. Berkebile, and S. R. Skoda. 1989. Comparison of three sampling methods for estimating adult stable fly (Diptera: Muscidae) populations. Environ. Entomol. 18: 513-520.

Received for publication 28 September 1993; accepted 28 October 1996. 